\title{
Comprehensive environmental assessment of innovative humic agro product
}

\author{
Natalia Kosolapova $^{1 *}$, Yekaterina Alferova ${ }^{2}$, Olga Miroshnichenko ${ }^{3}$, Elena Protsenko ${ }^{1}$, and \\ Natalia Balabina ${ }^{1}$ \\ ${ }^{1}$ Kursk State University, Environmental Monitoring Research Laboratory, 305000, Radishcheva st., \\ 33, Kursk, Russia \\ ${ }^{2}$ Kursk State University, Department of Biology and Ecology, 305000, Radishcheva st., 33, Kursk, \\ Russia \\ ${ }^{3}$ Kursk State University, Department of Chemistry, 305000, Radishcheva st., 33, Kursk, Russia
}

\begin{abstract}
There has been made the assessment of the product «CAVITA BIOCOMPLEX» quality parameters, manufactured according to the innovative technology of ultrasonic cavitation processing of peat in water medium at high static pressure. To carry out this assessment it has been used the universal system of procedure of comprehensive assessment of humic products. This system is based on the level approach. It was found that the sample of agro product in the capacity of the main bioactive components contains fulvic and humic acids (47.2-64.0\% calculated at dry weight basis). It is chemically and biologically safe for the environment. The usage of high-quality natural raw materials in combination with the "green" technology of "CAVITA BIOCOMPLEX" production makes it possible to use it not only as additional application with any mineral or organic fertilizers, plant protection products, herbicides, but also as basic fertilizer for biological agricultural technologies.
\end{abstract}

\section{Introduction}

Uniqueness of characteristics and structure of humic substances determines a high interest to the possibilities of their usage in agriculture. Industrial humic products are used as the stimulator of the cultivated plants growth, as ameliorants and soil detoxicant. The humic products made from carbonized materials (oxygenized low-cal brown coal and corresponding to it in the English-speaking terminology of lignite) are mainly presented in global manufacturing. Gumalit and leonardite are also used as oxygenized brown coal. There are also used peat, sapropel, wood waste processing and vermicompost. In such case the main method of humic substances' discharge is alkali extraction by ammonia-water mixture and potassium hydroxide and sodium hydrate. Alcaline conditions provide deprotonation of functional groups of acid character that leads to the destruction of bonds (primarily hydrogen bonds), stabilizing supramolecular assemblies of humic substances heterogeneous molecules, aggregates are dispersed and dissolved. Thus, in solution during the alkaline treatment are left humates and fulvates (salts of humic and fulvic acids or, in

* Corresponding author: nataliko7@yandex.ru 
other words, salts of humic acids) and work solution $\mathrm{pH}$ of the similar products is usually in the alkaline area (more than 9 units of $\mathrm{pH}$ ).

Limited liability company Trade and Manufacturing Company «CAVITA» has developed the innovative technology of ultrasonic cavitation processing of peat raw material in water medium at a high static pressure [1]. Manufacturing application of the mentioned technology allowed the company provide the output of the new agro product «CAVITA BIOCOMPLEX», which is paste-like mass consisting of dispersed peat of the field Dedovo pole in the Vologda Region of the Russian Federation and water. The peat particles are crushed without the help of alkaline agents due to appropriate choice of parameters that provides the greening of the manufacturing process and product's usage. The dispersed phase of product is presented by nanosize particles, which are prone to agglomeration with the formation of amorphous structures, the size of which is over the micrometric range [2].

All the components of peat complex are included in preparation formula. Humic substances are the basic components, for this reason giving an estimation of its useful quality we can use approaches to study traditional humic growth stimulators of cultivated plants [3]. Due to the fact that in the Russian Federation as well as in most foreign countries there is no certification system for humic products, there are also no unitized quality standards suitable for all types of this type of product. Different authors offer their own approaches for standardization and quality control of humic products $[4,5]$. In such case all the specialists pay attention to the importance of integrated assessment of humic products' quality, which can be done only according to the reasonable choice of parameters which are necessary for its implementation. There has been proposed a universal system of methodological techniques for the comprehensive assessment of humic products by O.S. Yakimenko and L.K. Sadovnikova [3]. This system is based on the level approach, which provides:

- assessment of the basic characteristics of humic products at the product's level;

- assessment of the basic characteristics of humic products at the associate's level;

- researches of humic products at molecular level, including the study of samples of humic substances isolated from industrial preparations;

- study of the biological activity of a humic products.

This approach has been used for studying quality parameters and environmental safety of innovative agro product «CAVITA BIOCOMPLEX».

\section{Materials and methods}

To characterize the product at the first level there has been done the definition of its organoleptical properties, content of solid matter, $\mathrm{pH}$ of saline suspension, $\mathrm{pH}$ of onepercent working solution, percentage of ash, weight percentage of organic matter, general content of the main plant food elements (nitrogen, phosphorus, potassium), gross content of macro- and microelements, including heavy metals and sanitary measurements. Sampling for testing of the product's different batches has been carried out according to GOST 54519 , the methods of metering are presented in the Table 1.

To assess the basic characteristics of the product at the level of associates, the extraction and quantitative determination of humic acids of its organic component using the method of Bambalov N.N., Belenkaya T.Ya. from the samples of different batches of the product according to the scheme (fig.1) has been studied [6].

To study the components of the product at the molecular level there have been done the spectroscopic studies of the samples of humic acids isolated from its composition during fractionation by the method of Bambalov N.N., Belenkoy T.Ya. 
Infared spectroscopy has been done by FTIR spectrometer «ФMC 1201» («FMS 1201») (Russia) in the form of tablets $\mathrm{KBr}$ in the range from 500 to $4000 \mathrm{~cm}^{-1}$.[7]. To investigate the absorption spectra of the products of alkaline-recovered humic acids in the ultraviolet (UV) and visible regions there have been done $0.001 \%$ solutions by applying of dissolving the corresponding samples in 0.1 molar solution (moles per litre) of hydroxide solution. Spectra have been recorded on spectrophotometer Shimadzu UV-1800 (Japan) in quartz cuvettes with a layer thickness of $1 \mathrm{~cm}$ in the range from 200 to $750 \mathrm{~nm}$.

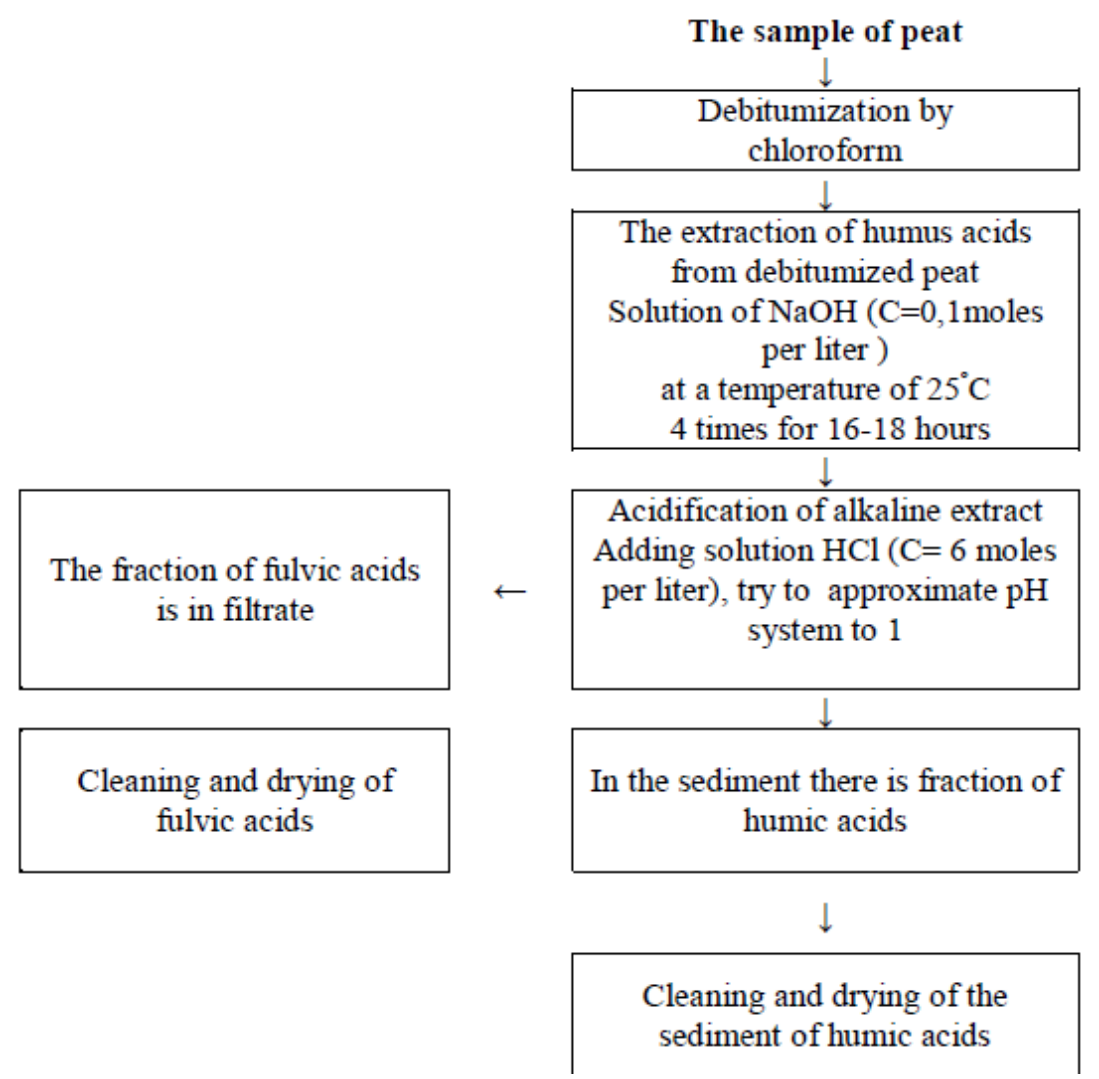

Fig. 1. The scheme of humic acids extraction from the agro product samples.

According to the estimation of the biological activity and the environmental safety of many physical and biological factors, chemicals, incl. naturally occurring, Allium-test has proved itself well. This test-system enables to reveal the mitostatic action or the mitostimulating effect of the factor and it also enables to reveal the dose dependence of the cytogenetic effect on the concentration of the acting substance [8].

To determine the influence of the different doses of the preparation on the root meristem Allium cepa there have been prepared the dilution series with the following concentrations: $0.1 \%, 0.25 \%, 0.5 \%, 1 \%, 2.5 \%$ and $3 \%$. The mitostatic action and the mito-stimulating effect of each solution have been estimated according to the standard procedure [9]. In parallel with it there has been done a determination of morphometric parameters of the plants, involved in the experiment, in particular, the average root length has been monitored. The research has been carried out with double frequency. The statistical processing has been done with the help of analysis package of MS Excel 2007. 


\section{Results}

The results of the research of the basic characteristics of the products at the first basic level are presented in the Table 1. There have been identified the averaged quantities of determined indicators, their change range from batch to batch and the coefficients of variation corresponding to these fluctuations.

Table 1. Base characteristic of agro product «CAVITA BIOCOMPLEX»

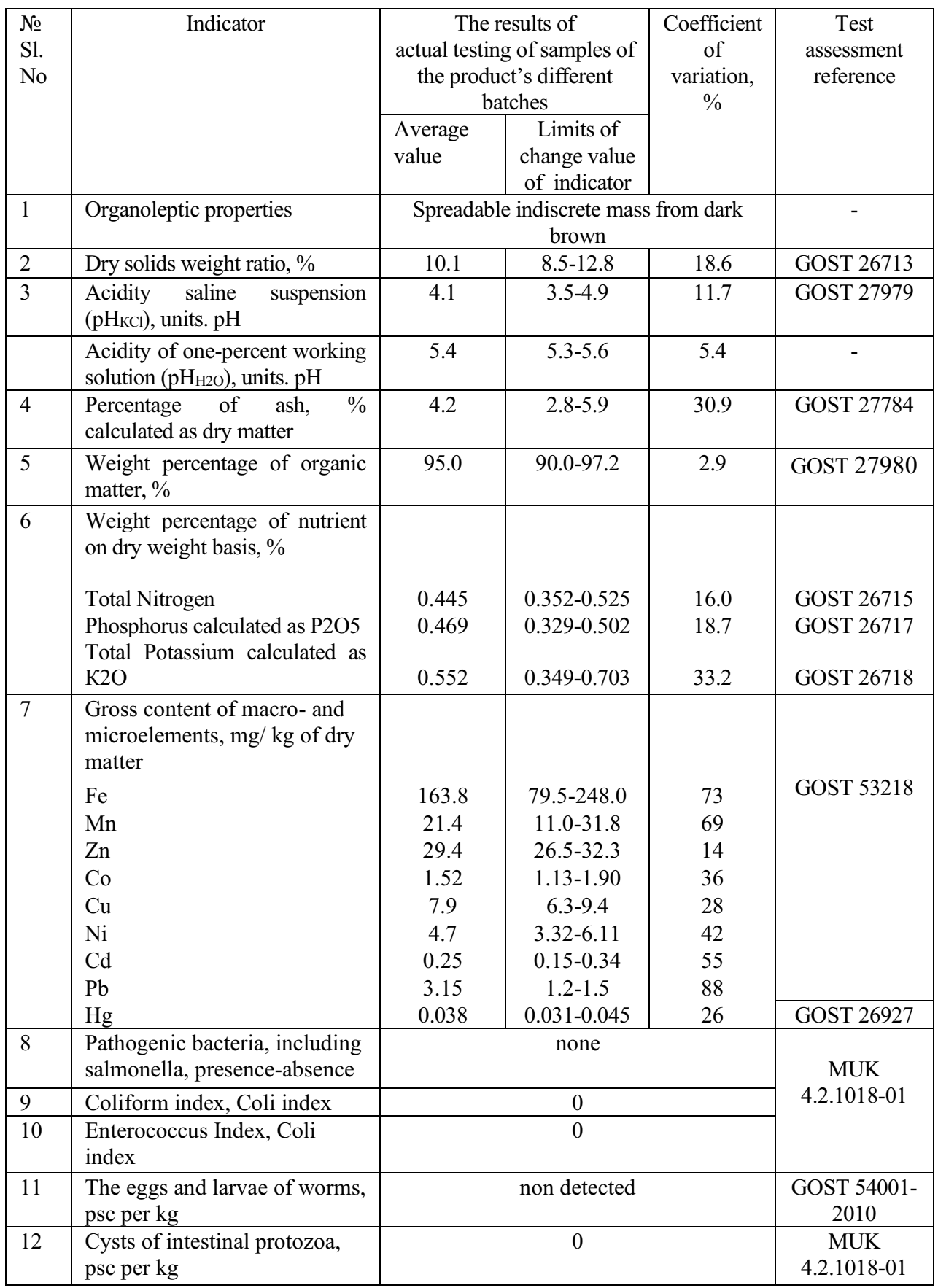




\begin{tabular}{|l|l|l|l|}
\hline 13 & $\begin{array}{l}\text { The larvae and pupae of } \\
\text { synanthropic flies, psc per kg }\end{array}$ & 0 & \\
\hline
\end{tabular}

The results of the quantitative determination of humus acids of the organic component of the researched product carried out as part of the assessment of its basic characteristics at the level of associates are presented in the Table 2.

Table 2. The content of humus acids in the samples of agro product «CAVITA BIOCOMPLEX», which have been tried and tested in different batches

\begin{tabular}{|l|l|c|c|c|}
\hline \multirow{2}{*}{$\begin{array}{l}\text { № } \\
\text { No }\end{array}$} & \multicolumn{1}{|c|}{ Indicator } & \multicolumn{2}{|c|}{$\begin{array}{c}\text { The results of } \\
\text { actual testing of samples of the product's } \\
\text { different batches }\end{array}$} & $\begin{array}{c}\text { Coefficient } \\
\text { of variation, } \\
\%\end{array}$ \\
\cline { 3 - 4 } & $\begin{array}{l}\text { Average value } \\
\text { Limits of change } \\
\text { value of indicator }\end{array}$ & \\
\hline 1 & $\begin{array}{l}\text { Weight percentage of organic } \\
\text { matter of alkaline fraction of } \\
\text { humus acids, } \%\end{array}$ & 53.9 & $47.2-64.0$ & $10.2 \%$ \\
\hline 2 & $\begin{array}{l}\text { Weight percentage of organic } \\
\text { matter of alkaline fraction of } \\
\text { fulvic acids, } \%\end{array}$ & 12.2 & $6.7-16.8$ & $29.0 \%$ \\
\hline 3 & $\begin{array}{l}\text { Weight percentage of organic } \\
\text { matter of alkaline fraction of } \\
\text { humic acids, } \%\end{array}$ & 41.7 & $31.1-57.3$ & $18.9 \%$ \\
\hline
\end{tabular}

* calculation of weight percentage of organic matter of each fraction has been carried out on absolutely dry matter of the samples

Absorption band in the IR spectrum of the testing samples gotten as the result of the research of the product's components at the molecular level and their assignment to the literature data [10-11] are shown in Table 3.

Table 3. Absorption band in the IR spectrum of the testing samples and their assignment to the literature data

\begin{tabular}{|l|l|}
\hline $\begin{array}{c}\text { Frequency, } \\
\mathrm{cm}^{-1}\end{array}$ & \multicolumn{1}{|c|}{ Band assignment } \\
\hline $3300-3500$ & Stretch vibration of $\mathrm{OH}$ group, hydrogen-bonded \\
\hline 2920 & Stretch vibration of $\mathrm{CH}_{2}, \mathrm{CH}_{3}$ group \\
\hline 2851 & \\
\hline $1680-1720$ & Stretch vibration of $\mathrm{C}=\mathrm{O}$ in carboxylic group, partly the others $\mathrm{C}=\mathrm{O}$ \\
\hline $1610-1630$ & $\begin{array}{l}\text { Skeletal vibration of aromatic structures, stretch vibration of interfaced carbon double } \\
\text { bonds } \mathrm{C}=\mathrm{C}, \text { etc. }\end{array}$ \\
\hline $1520-1500$ & Skeletal vibration of aromatic structures \\
\hline $1375-1460$ & Asymmetric and symmetric deformation vibrations of $\mathrm{C}-\mathrm{H}$ in $\mathrm{CH}_{2}$ - and $\mathrm{CH}_{3}$-groups \\
\hline $1240-1280$ & $\begin{array}{l}\text { Stretch vibration of the bond } \mathrm{C}-\mathrm{O} \text { of carboxylic group, alcohols, esters, deformation } \\
\text { planar vibrations of } \mathrm{OH} \text { bonds of alcohols and phenols }\end{array}$ \\
\hline $1030-1100$ & Stretch vibration of bond $\mathrm{C}-\mathrm{O}$ of carbohydrates, alcohols, cyclic and aliphatic esters \\
\hline 1150 & Stretch vibration of bond $\mathrm{C}-\mathrm{O}$ of phenol \\
\hline $720-730$ & Pendulum oscillations of $\left(\mathrm{CH}_{2}\right) n$-fragments $\mathrm{c} n \geq 4$ \\
\hline
\end{tabular}


The absorption spectra of the products of alkaline-recovered humic acids isolated from the composition of the examined agro-product samples in the ultraviolet (UV) and visible areas are characterized by the absence of clearly expressed absorption maxima in the 220 $750 \mathrm{~nm}$ area and it looks like a flat curve with a gradual decrease of optical density from 230 to $750 \mathrm{~nm}$. So, the absorption spectrum approaches to solid and the colour is close to achromatic. On the spectrum there is an absorption maximum in the $210-230 \mathrm{~nm}$ area, most probably corresponding to $\mathrm{p} \rightarrow \mathrm{p}^{*}$ transitions of polyenes, polyaromatic fragments and their oxygen-containing derivatives (K-bands).

As part of the analysis of the spectra there have been determined extinction coefficientit is E-value at $465 \mathrm{~nm}\left(\mathrm{E}_{465}{ }^{0,001 \%}\right)$ and the coloration coefficient, which is spectral coefficient representing the ratio of E-values for two wavelengths. The ratio $E_{465} / E_{650}$ expresses the steepness of the fall of the optical density according to increasing wavelength. It does not depend on the solution concentration and the thickness of absorbing layer [12]. So the argument goes that the coloration coefficient and extinction coefficient help to destine about the special aspects of the construction of humic acids and their degree of maturity. For humic acids isolated from the composition of the researching product these averaged parameters are 0.30 and 5.80 consequently.

The results of the Allium-test are shown in Figure 2.

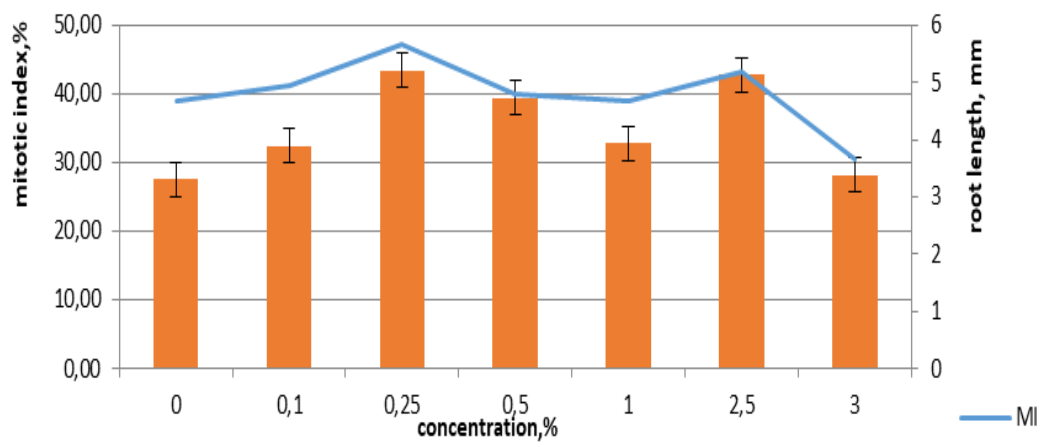

Fig. 2. The influence of the biopreparation «CAVITA BIOCOMPLEX» on cell fission of the root meristem and the development of root system Allium cepa.

It has been found out that both dependences of the identifiable parameters on the concentration have a bimodal character with maximums under the preparation's concentration of $0.25 \%$ and $2.5 \%$. They positively correlate with each other $(\mathrm{R} 2=0.78)$. It proves that there is no cytotoxic action.

\section{Debate}

As a part of the study of the product at the first level it is shown that the value of $\mathrm{pH}$ of working solution of the product "CAVITA BIOCOMPLEX» is over the range of 5-6 units of $\mathrm{pH}$.

It is determined that the samples of agro product are characterized by the content of basic nutrients at the level of $0.3-0.7 \%$ calculated on dry weight basis. The content of heavy metals in dispersed peat varies significantly from batch to batch. It can be related to the varying composition of the mineral component in the raw peat, used in the manufacture of the product within the field (coefficient of ash content variation is $30.9 \%$ ). However, all the achieved values do not exceed maximum permissible levels which are specified for soils, consequently, the use of the studied product in crop research does not lead to the accumulation of heavy metals both in the soil complex and in plant organisms. The 
presence of pathogenic microorganisms has not been detected in any of the studied batches of the product. It attests to the fact that using of the investigated agro product in agriculture is safe.

The analysis of the results got at the second level of the research and presented in Table 2 has showed that the main components of the organic constituent of the product are humus acids, which are important to provide the soil fertility and plant growing needs (47.2-64.0\% from the total content of organic matter). The high value of the coefficient of variation of the results of the content's determination of the fraction of fulvic acids (29.0\%) makes its conspicuous under low level of dissipation data which characterize the total content of organic matter and humus acids (2.9 and $10.2 \%$ consequently). It can confirm that during the process of production different batches of peat's products are used, their formation has been carried out in different conditions of transformation of peat formers, for example, peat from different depth of cover, which can be explained in the conditions of tonnage production.

Due to the high content of humus acids during soil application the product contributes to the improvement of the accumulative, regulatory, protective, biological and physiological properties of the soil and during foliar application it is used as a stimulator of growth and development of cultivated plants [2].

The results of the spectroscopic study of the humic acids isolated from the composition of the product according to the method of Bambalov N.N., Belenkoy T.Ya. confirm their belonging to the specified class of compounds. In such a way in infra-red spectrum of humic acids there are all absorption bands which are characteristic for these compounds, absorbance spectrum of the humic acids solutions in the ultraviolet and visible regions have also the suitable view.

As part of the analysis of the spectra in invisible range there have been determined extinction coefficient $\left(\mathrm{E}_{465}{ }^{0,001 \%}\right)$ and the coloration coefficient $\left(\mathrm{E}_{465} / \mathrm{E}_{650}\right)$. these parameters are 0.072 and 1.35 consequently and they are in the range characteristic for humic acids [12].

The use of high-quality natural raw materials in combination with the "green" technology of production of agro product "CAVITA BIOCOMPLEX" makes it possible to use it not only as additional application with any mineral or organic fertilizers, plant protection products, herbicides, but also as basic fertilizer for biological agricultural technologies. As a result, it has been proved by the results of a comprehensive environmental assessment of the main quality parameters of the researched product.

\section{References}

1. A.V. Smorodko, O.V. Volodina, Patent 2533235 the Russian Federation, The way of getting biogel. Biogel., Bulletin. 32, publ. on November 20 (2014)

2. N.I. Kosolapova, E.P. Protsenko, A.A. Protsenko, N.P. Nevedrov, E.Yu. Alferova, O.V. Miroshnichenko, Problems of the regional ecology, 3, 24 (2016)

3. O.S. Yakimenko, L.K. Sadovnikova. The methods of the research of organic matter of soil (Rosselhozakademiya, GNU VNIPTIOU, Moscow, 2005)

4. B.V. Levinskiy, All about the humates. (Corf-Polygraph, Irkutsk, 2000)

5. L.K. Sadovnikova, O.S. Yakimenko, Yu.N. Bogachenko, N.A. Edessheva, The materials of the Second International Scientific and Practical Conference "Earthworms and Soil Fertility". 253 (2014) 
6. T.V. Dementieva, O.Yu. Bogdanova, N.A. Shinkeev, Physicochemistry and biology of peat. A guideline for the methods of studying the transformation of organic matter of peat: methodological rationale (Tomsk CSTI, Tomsk, 2011)

7. D.S. Orlov, L.A. Grishina, Workshop on chemistry of humus, Instructional medium (Moscow Publishing house of Moscow University, Moscow, 1981)

8. A.S. Sheremeteva, Expert opinion. Collection of articles of the International Scientific and Practical Conference, part 1, 21 (2017)

9. O.P. Melekhova, E.I. Egorova, T.I. Evseeva, V.M. Glaser, Biological control of the environment: bioindication and biotesting (Publishing center "Academiya", Moscow, 2007)

10. A.Kh. Kuptsov, G.N. Zhizhin, Fourier spectrum of combination scattering and infrared absorption of polymers. Reference book (FIZMALIT, Moscow, 2001)

11. E. Prech, Determination of the structure of organic compounds. Tables of spectral data (Mir; BINOM, Laboratory of Knowledge, Moscow, 2006)

12. D.S. Orlov, Humic acids and general theory of humification (Publishing house of Moscow State University, Moscow, 1990) 